\title{
Team Decision-Making and
}

\section{People-Organization Matching-Based on the Adjustment of Implicit Coordination and Task Interdependence}

\author{
Yuhua Sheng, Fan Xu* \\ Business School, Nanjing Normal University, Nanjing, China \\ Email: *2907158119@qq.com
}

How to cite this paper: Sheng, Y.H. and Xu, F. (2019) Team Decision-Making and People-Organization Matching-Based on the Adjustment of Implicit Coordination and Task Interdependence. Journal of Human Resource and Sustainability Studies, 7, 416-437.

https://doi.org/10.4236/jhrss.2019.73028

Received: August 26, 2019

Accepted: September 15, 2019

Published: September 18, 2019

Copyright $\odot 2019$ by author(s) and Scientific Research Publishing Inc. This work is licensed under the Creative Commons Attribution International License (CC BY 4.0).

http://creativecommons.org/licenses/by/4.0/

\begin{abstract}
Talents are the core competitiveness of enterprises. In high-tech enterprises with team work as the mainstay, the recruitment and selection of team members has always been a concern of enterprises. As the first module of human resource management, recruitment is an important task of human resource management and development. Whether a company can recruit the people it needs is the key to the success or failure of the company. This paper analyzes 300 valid samples using stepwise regression analysis, and analyzes team work characteristics to study team self-determination within the team. The recruitment effect is measured in this paper using human-organization matching. The research results show that team independent decision-making positively affects human-organization matching. Task interdependence and implicit coordination have a significant positive adjustment effect on the relationship between the two. The research provides a new way for enterprise personnel recruitment.
\end{abstract}

\section{Keywords}

People-Organization Matching, Team Decision, Task Interdependence, Recruitment Decision

\section{Introduction}

With the changes in the market environment, the demand for new technologies and social individualization is increasing since the high-tech enterprises have emerged. The working methods of high-tech enterprises are the way of team work, and the selection of staff in the team is always a big problem for high-tech 
enterprises. Today's talent market has a typical "Matthew effect", but the service industry and other talents are crowded, while the technical personnel in high-tech enterprises are seriously lacking, and the supply of talent market is far from meeting the talent demand of emerging technology companies. High-paying technology companies need professional, thoughtful, forward-looking people and high-tech talents to determine the future of the company, and such people are often not found in the general talent market. Based on this, this paper proposes the new ideas and recruitment angles of high-tech enterprises by studying the working methods and recruitment strategies of Bell Labs and proposing the relationship between team decision-making and people-organization matching.

In the high-tech enterprises, the team work style has replaced the traditional part of the work mode and the functional work mode. In the era of knowledge change and the highly competitive globalized knowledge economy, the realization of organizational innovation by the team has become the main means for the organization to gain competitive advantage. In the current high-tech industry, how to choose and attract the right talents to become a member of the team is very concerned. From the development process of Bell Labs and the recruitment mechanism, the author finds that the middle working team of Bell Labs has great decision-making power of the team. As long as it conforms to the general development strategy of the enterprise, the staff can decide how to complete the work or even have the right to introduce new talents to participate in the work. The tasks of senior managers and other personnel in the enterprise are to assist the core staff to meet the material requirements of the staff or other aspects of the work content without interfering with the researchers. The use of senior management is an open management tool. They do not take command-based guidance for employees. They are more concerned with the worries of researchers and supplemented by supervision and guidance. It is the reason that Bell Labs can attract the top talents in the industry to join the laboratory. Bell Labs will be at the forefront of the world and develop one after another innovative scientific and technological achievements. Thinking about the selection method of Bell Labs, the staff members can decide the colleagues who work with them, which not only allows the old staff to have a deeper sense of belonging to the company, but also reconciles the adaptation status of the new company after entering the enterprise. Domestic enterprises can also adopt this recruitment method for talent recruitment. Of course, not all enterprises can adapt to this recruitment method. The determination of recruitment methods depends on the development direction and organizational structure of the enterprise. A smart enterprise should consider comprehensively. The current status of the organization and the future direction of development determine the specific recruitment strategy and recruitment methods. Nowadays, the competition among enterprises in the era of knowledge economy is the competition of talents. It is extremely important to grasp the selection and recruitment of talents. Recruiting employees who are suitable for enterprises can retain employees for a long time, gain more benefits for the company and lay a good foundation for the future of 
the company.

As an important part of human resource management, the recruitment of employees shows mainly two perspectives such as job analysis and individual ability test. Job analysis can provide job requirements and individual ability to examine candidates. The degree of individual ability test, that is, the requirement of "requirement-capability" complementation is an important criterion for personnel selection decision-making. The recruitment principle based on the matching of people and work focuses on the integration of individual and work. The enterprise value is the knowledge of employees, skills, abilities and job suitability. However, in the actual recruitment of enterprises, there is still much room to improve something in the matching of people and work. As the jargon of the recruitment industry said, "the enterprise recruits skills and dismisses them". Businesses usually hire someone because of someone's skills, but they don't take into account the quality of the recruited person or the ability of the team to work. This creates hidden dangers for future work, because it is not suitable for the company's strategy, culture and value and ended up with dismissal. This kind of limited recruitment method is more obvious in industries with rapid changes in technology and market environment, such as high-tech enterprises. Therefore, it is necessary to propose new recruitment methods for high-tech enterprises such as rapidly changing enterprises. According to the recruitment method proposed by people-organization matching, enterprises should also pay attention to the matching between the inherent characteristics of individuals and the organizational culture of enterprises. In today's high-tech enterprises, the $\mathrm{R} \& \mathrm{D}$ team is the main way of working. For recruiters, selecting talents is not only to match people and positions, but also to match people and teamwork in small groups. The recruitment strategy has undergone a fundamental change. From the previous unified recruitment to the team's own decision-making recruitment, the company decentralizes the power to the specific team work. The team members find the most needed talents in the team that can speed up the team. The efficiency of the work and the motivation to motivate the team's work are a good way to do it. At present, the research on team work is more focused on team work efficiency and team creation. It also mentions the advantages and disadvantages of team decision-making power in team work, and decentralizes the power of human resource management to the team. As far as the current team work style is concerned, the decision of the new team members through team decision-making can alleviate the exclusionary pressure that new members will face and improve team work efficiency.

This paper takes high-tech enterprises as the research object, and selects the work team of high-tech enterprises as the research object. It conforms to the general trend of market enterprises in recent years. Exploring the relationship between team independent decision-making and the matching between people and organizations can bring good selection principle to more high-tech enterprises in order to reduce the cost of employing people and improving performance. However, the samples studied in this paper can not represent the devel- 
opment situation of each region, because of the characteristics of the team work content are differences between the teams are also essential. In this paper, there is no specific research on the differences between different work content teams. More influencing factors should be considered in future studies to achieve more accurate results.

\section{Literature Review and Theory}

\subsection{The Autonomy of Personnel Decision-Making in Team Work}

Research on team decision-making has been studied from small groups of traditional social psychology, as well as group studies in organizations. Social psychologists study team decisions through teamwork in the lab; With the organizational structure built around the team work style in the organization, the focus of psychologists is gradually shifting to team decisions in the enterprise. The team work form is constructed into an organizational structure, the team work form replaces the individual work form, and the corresponding team decision becomes the decision-making method generally adopted by the organization [1]. The traditional personnel management work is more prominent in "management", and the opinions of leaders of enterprises and institutions can often play a decisive role. The reason is mainly that the power is more concentrated in the administrative structure, but the specific implementation is blocked at the same level. On the one hand, the personnel management department within the enterprise is responsible for decision-making, but the management personnel know little about the characteristics of the posts and employees; On the other hand, the functional division in the enterprise can bring convenience to the operation, and at the same time, the functional departments cannot participate in the personnel deployment. In the decision-making, this has caused the use of human resources to differ from the actual needs of the enterprise, and failed to give full play to the personal strengths of the employees. In addition, the excessive concentration of decision-making power will make the traditional personnel department lack autonomy and be seriously out of touch with the employment of employees. These factors will hinder the introduction and cultivation of talents in enterprises, which is not conducive to the formation of effective mechanisms for entry, management and exit. Yuanming (2014), who has many years of management experience, once said in "Let's do the best in recruiting": "Recruitment is like a puzzle. We find a picture that is closely and seamlessly connected with the corresponding parts of the company, so that we can complement each other." [2].

In the previous research of team decision-making, a variety of team decision-making models appeared, but there is no unified decision-making model. The reason is that the team decision-making model is formed by different team tasks. Researching existing literature can summarize the team decision-making model into the following four types. Social decision-making schema, that is, focusing on the predictive effect of member bias distribution before team mem- 
bers' discussion on the final group decision [3]. Project sorting tasks, team members independent Project sorting [4]. Sampling model is based on the task design of shared information and non-shared information [5]. Multi-level team decision theory, which differs from the other three models in that it considers the complex environment in which the team is located [6], this is a dynamic team decision model.

The core of team decision-making lies in the different general personnel decision-making bodies of decision-making bodies. The main body of personnel selection in team decision-making is the team members who participate in team work. The main body of such recruitment decision-making can clarify the criteria for candidates' recruitment and the candidates in terms of skills. The requirements are more in line with the work content, and the team's autonomy decision-making takes into account the teamwork ability, and the team decision-making body is bound to be able to select the person who is suitable for the team work. Recruitment decisions based on team decision-making are different from traditional recruitment methods in China. This kind of recruitment method reflects that part of the human resources responsibility is dispersed into the work team, and on the other hand, it reflects the selection of high-tech enterprises such as rapid development of enterprise personnel. Particularity and the improvement of the strategic can use position of human resources.

Wan Hao (2012) had different understanding of recruitment In the traditional concept, he regards recruitment management as the following management activities in the organization: recruitment, screening, hiring and evaluation [7]. On this basis, planning, organizing, directing and controlling to ensure a certain number of research teams to meet the needs of organizational development. The traditional recruitment is for the recruitment of personnel lacking in corporate positions [8].

Yang Qiurong's (2008) [9] research shows that the organization through scientific and effective methods, the selection of talents that meet the organization's survival and development, and the behavior of hiring and management is called recruitment management. Zhu Jun (2010) proposed a more comprehensive recruitment evaluation indicator, which is mainly measured by the thinking dimension: recruitment cost, recruitment results, recruitment channels and the quality of new members. As the Internet goes deep into our lives, Xu Fang (2007) discusses the role of intermediary in the network. Under the paper, an empirical study on the effectiveness of recruitment is carried out, and an effective model for network recruitment of labor market intermediary organizations is proposed and established [10]. In addition to assessing the effective model of recruitment proposes more operational evaluation indicators for the recruitment phase, which also consider the industry, geographical location, recruitment positions and recruiter standards of the company as factors. ALKristof (1996) compares the characteristics of effective recruitment and invalid recruitment. The recruitment evaluation indicators are refined into the timeliness of recruitment, 
recruitment costs, employee turnover rate, employee satisfaction, employee morale and risk of recruitment [11]. In the study on how to improve the effectiveness of recruitment, Liu Weihua (2006) put forward the importance of cooperation between the human resources department and the linear department, and proposed a feasibility study to enhance the recruitment plan; Career skills training and innovations that focus on recruitment methods to improve the effectiveness of corporate recruitment. By recruiting talents through recruitment, we will promote the rational use of internal resources of the company, and make the employees' internal structure more in line with the strategic development needs of the organization.

McGregor (1960) proposed the management principle of "target integration", which is to create conditions for the members of the organization not only to achieve their goals, but also to pursue the success of the organization, indicating that the organization is in a win-win situation. Although the goal fusion concept has been proposed for more than half a century, there are not many companies that can truly integrate organizational goals and employee goals (Scott \& Davis, 2007). At the same time, in the management of many enterprises, the traditional formal organization management model essentially hinders the individual development and self-realization of employees. In the long run, it will dispel the competitive advantage of the organization and it is difficult to achieve the organizational goals. Solutions to the consistent realization of individual goals and organizational goals have suggested that corporate training can strengthen organizational goals, organizational climate can affect employees in a subtle way, but companies have to consider the costs and benefits. As far as the actual situation is concerned, the efficiency of training is low, and the subtle influence of the atmosphere is difficult to guarantee the realization of the ultimate goal. Therefore, paying attention to the similarity between the candidate's goal and the organizational goal when recruiting personnel is a worthy consideration, and on this basis, it is more in line with the human-organizational match. The organizational goal refers to the state of development that the enterprise as the operating entity is eager to achieve in the future. The employee goal refers to the valuable, relatively stable future state that the individual desires to achieve [11]. Therefore, this paper studies the impact of the team's self-determined recruitment model on human-organizational matching.

\subsection{People-Organization Matching}

Although there is no complete definition of the match between people and organizations, the matching of people and organizations has attracted the attention of many scholars. Some scholars have suggested that there are two major levels of consistency matching and complement matching in the understanding of matching. Muchinsky and others believe that the similarity between individuals and other members of the organization or organizational culture is consistent [12]. Complementary matching focuses on whether individuals have unique re- 
sources. These unique resources can be used to fill the gaps in the organization, and complementary matching is often used as a criterion in individual career choices and organizational selection studies. In some studies, the demand-supply perspective and the demand-capacity perspective are different. From the perspective of the organization, the demand supply perspective is put forward and the organization meets the needs and preferences of the individual. The demand is matched. The point of view is that when an individual has the capabilities that an organization needs, the match is achieved. Kristof (1981) written "task performance should be distinguished from contextual performance" in summarizing previous studies based on the following, the following model of matching people with the organization is proposed, as shown in Figure 1.

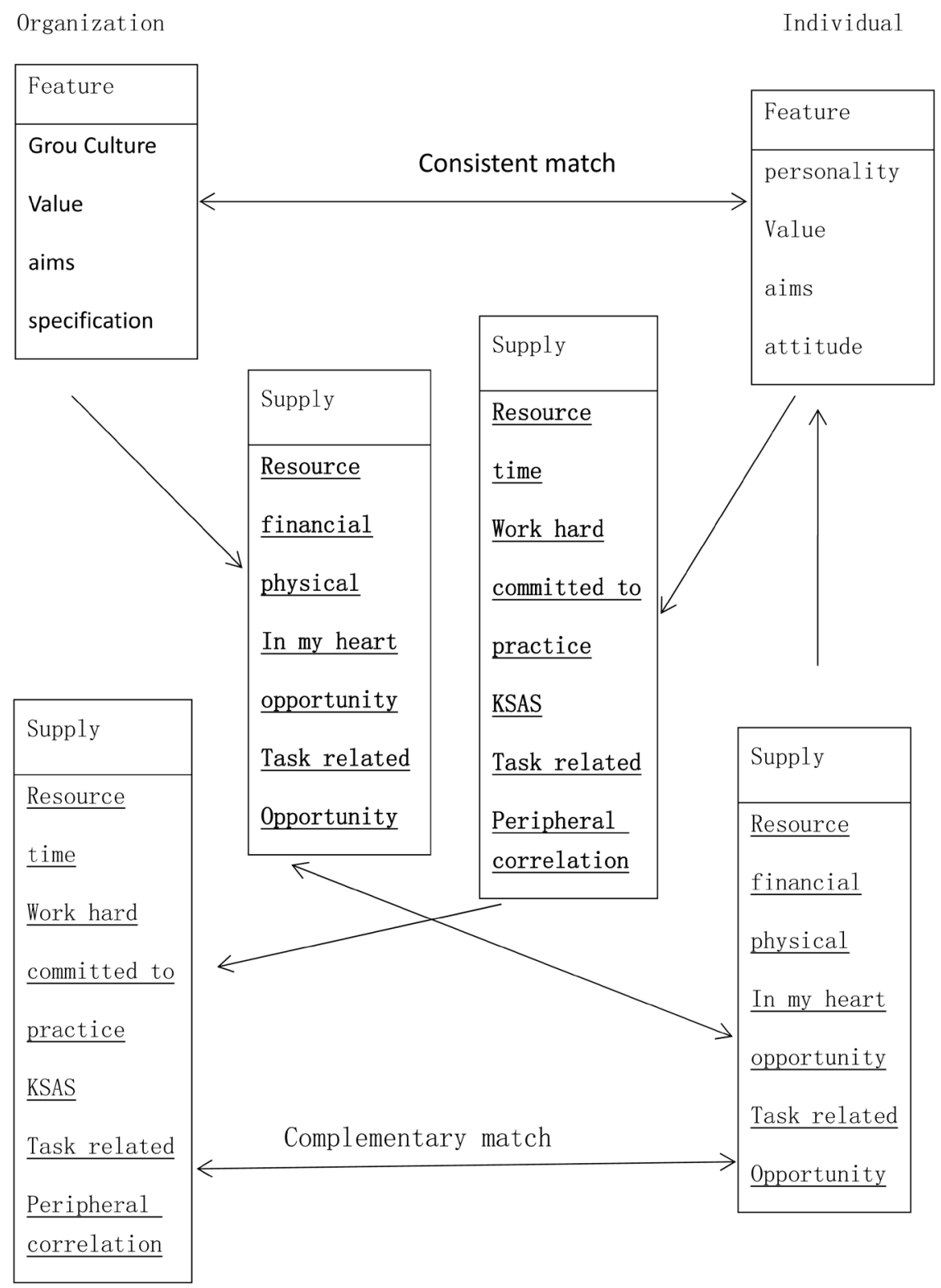

Figure 1. Integraed framework model for matching people and organizations. 
The model integrates the concepts of consistency matching, complement matching, demand-supply matching, and demand-capability matching. It believes that consistency is achieved when the basic characteristics of the organization and the individual are similar. The basic characteristics of the organization are organizational culture, values, goals and norms. Individual characteristics are individuality, values, goals and attitudes. There are similarities in these respects based on individuals and organizations. The matching between people and organizations mainly covers two aspects, such as the organization provides financial, physical and psychological resources, provides opportunities for work development and interpersonal interaction; the individual provides its own time, effort, commitment and other resources to meet the requirements of the organization in these aspects. Kristof (1981) believes that matching people with organizations requires at least that people and organizations can provide the resources that one party needs. Similar features, or both, are achievable.

The ultimate goal of recruitment is attributed to the matching of people and organizations, and compared with the purpose of recruitment and the matching of people's work. Selecting talents that focus on matching people and work is more concerned with finding employees than retaining them. However, in the development of the company, we understand that talent is the top priority, not only to discover employees, but also to cultivate enterprises. This is not what human work can do. The advantages brought by the matching between people and organizations reflect the improvement of employees' work attitude, lower turnover rate and improve employee performance. Some related studies have provided evidence for this. For example, in most studies, human-to-organization matching has a positive impact on individual-level outcome variables. Closely related to the employee's work attitude is the consistency of values and the consistency of goals. The consistency of values brings about the cohesiveness of individual incentives and perceived work teams [13].

When 356 principals and 14721 teachers in the United States and Canada were used as research objects, the results of the study indicate that consistency between supervisors and subordinates and consistency between employees are positively affecting job satisfaction and organizational commitment [14]. Motowidlo (1994) and others proposed the concept of distinguishing between task performance and peripheral performance [14]. Goodman studying of the relationship between human and organizational matching on task performance and peripheral performance shows that human-to-organization matching can predict peripheral performance and task performance. Chinese scholars Zhang Wei, Zhang De and Yu Dan (2008) and others used Xi'an 742 companies as samples, and found that the expected matching degree positively affects job satisfaction and organizational commitment, while negatively affects the intention to leave. The common research is to change the recruitment process or the recruitment method for human-organization matching, and does not fundamentally change the formulation mechanism of recruitment decision. This paper discusses the decentralization of personnel decision-making power to the work team. In order 
to see the impact on human-organizational matching.

\subsection{Task Interdependence}

So far, there are two different viewpoints on the study of task interdependence. "Essence" is one of them. It is considered that task interdependence is the essential attribute of work tasks [15]. That will not be influenced by humans. The other is "behavior theory", which means that task interdependence reflects how people behave when they complete tasks. According to which, by designing tasks of different task interdependence levels, the degree of interaction of members is in completing a task [16].

Currently, research indicates that team work processes and team outputs are related to task interdependence. In the process of team work, task interdependence has a positive impact on helping behavior, prosocial behavior, and organizational citizenship behavior. In addition, some studies have found that task interdependence also helps to promote team communication [17]. The Mediating Effect of Cross-functional Communication on the Relationship between Task Interdependence and New Product Development Speed: A Proposed Model shows that there is a nonlinear relationship between task interdependence and team performance. The nonlinear relationships found will follow The difference in the type of task changes. In addition, there are many studies that demonstrate the impact of task interdependence on other team outputs from an empirical or theoretical inference perspective. Flood believes that perceived task interdependence can positively influence team loyalty. Ren et al. using a questionnaire survey method, found that task interdependence can be positive commit to the impact team. Darawong (2013) believes that task interdependence can affect new product development Speed and put forward the concept of inter-functional communication [18]. Through the research of 70 work teams, Wang Yanzi's (2014) research shows that task interdependence will influence the team's creativity through the team's learning ability. From the current research, one of the important input variables of team research is task interdependence, which has a significant impact on the team work process and team output. In addition, researchers such as Sambasivana extended the definition of task interdependence and defined the degree of interdependence between businesses. The research shows that task interdependence can positively influence the relationship capital of enterprises in strategic alliances, which is enough to show that task interdependence is not only related to the team or individual level, but also to the organizational level.

Incorporating the interactions required for the work in the first six job characteristics, whether a task needs to be active or passive to interact with other members is considered to be a feature required for the job [19]. Kiggundu (1996) also considers a significant feature of work as task interdependence, which will be the task. The concept of interdependence covers three levels: the first is the scope of task interdependence, that is, the breadth of the relationship between a 
particular job and other work. The second is resources, that is, a specific job. To what extent is it providing and receiving important resources with other work. The third is critical, which refers to the extent to which a particular job performance can be affected by other related job performance. Campion (1993) indicates that interdependence is an inherent feature of the team and also forms a team. The reason, therefore, interdependence will affect the efficiency of work completion. Wagenna (1995) considers interdependence there are two types, one is task interdependence, which indicates the degree of existence dependence between work input and workflow distribution [20]. The other is result interdependence, which refers to the achievement of work goals and the degree of dependence between rewards. Position the task interdependence as the task that each member needs to accomplish in completing a task. It can be seen that the work can be divided into high work response. A highly interdependent work requires more people to complete the task, each of whom has to perform his or her own tasks to complete the work; A highly independent work is a work that can be done by individuals, such as research and development. Work is not only personal research and development, but also team research and development. Slocum shows that task interdependence can determine to some extent the degree of control and autonomy given at work.

In the case of high interdependence of tasks, an employee cannot complete all the work by relying on the resources and resources from other members. The collision and recombination of the knowledge structure of the innovation differences generated in the team. It enables the staff to clearly understand the advantages and disadvantages of the work content, which can improve the efficiency of the independent decision-making in the work team. To maximize the efficiency of the team work, the team is rooted in the organization, thus further deepening the match between people and organizations. Wittenbaum (1996) considers task interdependence to be the degree of communication and dependence between employees required to complete a task. In summary, this article will draw on Zhang Yixiang's (2010) definition of task interdependence, and believe that task interdependence is the degree of mutual exchange and dependence of team members at work.

\subsection{Implicit Coordination}

Team coordination can be divided into explicit coordination and explicit coordination according to the way of presentation. It refers to the organization's strategies and behavior patterns in order to achieve the team's goals. Explicit coordination refers to the adjustment of the organization through direct interaction of members or external media, such as mutual communication, standard workflow or code of conduct. Team implicit coordination can be used as a new form of team coordination, with team members adjusting their behavior based on predictions of tasks and other members' needs. The discussion of external coordination has been going on for many years, and with the study of cognitive 
behavior, more scholars believe that implicit coordination can also achieve tacit cooperation and division of labor. The difference between implicit coordination and explicit coordination is that implicit coordination is more an unconscious and subtle self-adjustment process. Studies have shown that implicit coordination also affects the effectiveness of explicit coordination, and also positively affects the cooperative effect of team members. Therefore, many scholars intend to study the operation mechanism of implicit coordination, in order to improve the efficiency of team work from implicit coordination. Wittenbaum, Stasser and Merry (1996) believe that implicit coordination arises from the correct perception of the task by employees. From the perspective of knowledge, Nrico (2008) found that implicit coordination is constantly developing and improving in the context of team work. However, these studies do not take into account the dynamic coordination of implicit coordination of cognitive structure and operational processes. With the fierce market competition, the emergence of implicit coordination provides a new way of thinking for the team to gain competitive advantage.

Team members' perceptions of tasks, expertise, and people's matching are key factors for implicit coordination, or they can be expressed as three key elements that are both related to each other: task evaluation, member expectations, and resource allocation. The task evaluation includes "what is the task" and "how to complete". The three main contents are the performance standard of the task, the expertise required by the task, the strategy to complete the task, and the task evaluation can effectively guide the interaction between the team members. The performance criteria of a task can determine the degree of interdependence between team members. In addition, the individual's expectations of others and their own resource allocation are influenced by the expertise required for the task. Implicit coordination is based on whether the team is able to accurately identify a member's expertise, and the member's actions in the task depend on the expertise and competencies of other members of the same group. Therefore, implicit coordination is used in this paper to adjust the relationship between team autonomy decision-making and person-organization matching, so as to verify that the recruitment work in high-tech enterprises should not only pay attention to the characteristics of outside talents, but also pay attention to the work groups.

The organizational structure of this paper is as follows. First, learning the existing literature on team work obtain knowledge and thinking. It is necessary to understand the related factors between recruitment and team work for selecting team independent decision making as the independent variable of this paper and human-organization matching as the dependent variable of this paper. It is observed that the implicit coordination and task interdependence of the team will affect the relationship between team independent decision and human-organization matching. In addition, the team work style of high-tech enterprises is selected as the research object, and the data is collected online through questionnaire survey. The research sample is formed through screening and data processing. The 
adjustment model of team independent decision-making and person-organization matching under implicit coordination and task interdependence is established. The hypothesis between variables proposed in this paper is verified by SPSS2.0. The verification results show that the team's independent decision-making influences the person-organization matching. The implicit coordination and task interdependence play a regulatory role in the team's independent decision-making and human-organization matching.

\section{Research Hypothesis}

\subsection{Team Self-Determination and Human-Organization Matching}

Team self-determination is very likely to achieve the fit between people and organizations, and this kind of fit can improve the level of team operation under the joint effect of member characteristics and organizational environment. From the perspective of value matching, individuals' role orientation and task orientation increase with the improvement of value level. At the same time, members are more willing to pay more energy to their team. Hulsheger and other methods through meta-analysis yielded five categories of factors that have the strongest predictive effect on team innovation. Among them, the first condition for achieving organizational innovation is the common goal of team formation. From the perspective of capability-requirement matching, the degree of matching is the individual's skills in related fields. In high-tech enterprises, members who have mastered a variety of unique knowledge gather in one team and can play the advantage of team heterogeneity resources. The key is to highly integrate the diverse skills of different members. Team work style is the core work mode of high-tech enterprises. As a core competitiveness, team members further reveal why high-tech enterprises are the primary choice for most staff with unique capabilities.

The primary requirement of the team's working style is the complementary cooperation of the team. It also requires the team members to choose not only the skill complement but also the personal characteristics of the employees. In the study of organizational behavior, it is shown that a major factor affecting employee enthusiasm is interpersonal relationship. Relevant research proves that higher-capacity employees can improve and share the original knowledge structure, so as to get rid of the inherent state of work, absorb and explore self-efficacy. Sense and willingness to innovate, work harder to help the team get rid of the low level of creativity. Some scholars have also shown that employees with unique personalities and outstanding performances, such as skills, experience and psychological expectations. It is difficult to achieve the existing level in the team. In the demand-supply matching, when the team has a sound assessment and reward mechanism, a good leadership-member relationship, and a positive organizational support atmosphere, the organization can achieve the individual's expectations, that is, the psychological resources mentioned above. With the development opportunities of learning, such incentives can mobilize the enthu- 
siasm of employees and encourage them to contribute more to the organization. The social exchange theory further proves that under the above-mentioned scenarios, members can have a actively return the organization where the employees are located, and improve the efficiency of the team. Based on this, this paper proposes the following assumptions.

H1: Team self-determination is positively related to people-organization matching.

\subsection{Task Interdependence}

Task interdependence refers to the degree of interdependence of team members in terms of work tasks, which reflects how much team members think they need to rely on others to complete their work. The interaction of team members and the behavior of cooperation are the basic characteristics of the team's operation. The interdependence of tasks specifically illustrates this basic feature. In a task-oriented team, team members have a basic understanding of each other's abilities and expertise, so team members can coordinate their behavior to better accomplish tasks with others. Extremely, when the various tasks in the team are highly interdependent, members naturally need to share all kinds of information and knowledge to complete the task quickly and accurately. At this time, there will be certain requirements for the staff in the same team. When the team members are at the same level, they can understand each other's shared knowledge or can quickly learn the core knowledge, which will inevitably work for the team. Bring high efficiency. At this point, it is necessary to consider the structure of the team, the composition of the team members, and the uniqueness of the team work in high-tech enterprises requires a high degree of professionalism and tacit understanding. This requires new selection methods in selecting team members, which involves recruitment. Checking the relevant literature and analyzing the unique domestic and foreign enterprises, founding that Bell Labs of the United States participated in the selection of newcomers who chose to work with themselves. The domestic Haier Group was able to fully select the self-selection of the work team. The selection of the right to the relevant work groups can greatly improve the efficiency of recruitment, reduce the rejection and competition awareness of the new members when they enter, thus saving time and cost and related coordination of labor costs, so that new and old employees can interact with each other as soon as possible. Adapt and integrate into the work. At the same time, the benchmark of recruitment decision based on team members is the embodiment of team work appeal. The selection of new employees must be demand-matching, and the formation of team is also the orientation of organizational value. The new employees also meet the complementary needs. Interdependence has a regulatory effect on team independent decision making and human-organization matching. Based on the above review, the following hypothesis is proposed:

$\mathrm{H} 2$ : Task interdependence will regulate the relationship between team autonomy and human-organization matching. 


\subsection{Implicit Coordination Regulation}

Implicit coordination is a tacit understanding of team member cooperation. Team members form this rapport with accurate, shared understanding and expectations of relevant key elements. Therefore, the cognition at the team level indicates that the following characteristics are necessary for the key elements of implicit coordination: First, whether members can accurately recognize key elements, that is, the degree of similarity between members' expectations and facts; Whether to share key elements, if not, the team will have difficulty meeting the tacit understanding of working together. On this basis, the continuous updating of key elements by team members can achieve the accuracy and sharing of implicit coordination.

A series of interactions that team members build and evaluate when they do not apply key elements are called implicit coordination operations. For a build of knowledge about task, expertise, and human matching, what team members need is a combination of relevant tasks, members, and cognitive segments of related expertise. The ability to facilitate the construction of this cognition is all about team members, such as member materials, collaborative experience, formal task assignments, or communication between members. Promoting coordination among members of the team is a key element of high reliability. Conversely, team members take measures to promote coordination within the team, such as re-analysing relevant clues and updating cognition of key elements. In the end, the team members will adjust their behavior according to the key elements of matching, directly hand over the relevant tasks to the other party or retrieve knowledge from the relevant personnel. This is called implicit coordination application. Implicit coordination is expressed as whether the employees in the team have a work tacit understanding. The effectiveness is that the members of the team can clearly understand the information of the team tasks and cooperate with each other. More researchers use the implicit coordination of the team as a mediator variable. This is due to the mechanism of implicit formation. The implicit coordination of the team does not exist when the team starts to be built. The implicit coordination exists in the team members. At the same time, implicit coordination will in turn affect the performance of team work. In this respect, it also has an impact on the team's decision-making. The team decision is derived from the joint decision of the team members. The decision is influenced by the personality characteristics of the decision makers and the environmental information. Influence, Simon's decision theory shows that there is no best decision, only better decision, because of the limited rationality of man. In today's fast-growing industry, the decision-making is dynamic, not only because of the limited rationality of people, but also because of the rapid changes in the market that enterprises face. Therefore, team decision-making not only compensates for the limited rationality of individual decision-making, but also makes appropriate adjustments to the team structure under the influence of implicit coordination within the team. Based on this, the paper proposes the following assumptions.

H3: Implicit coordination will regulate the relationship between team autonomy 


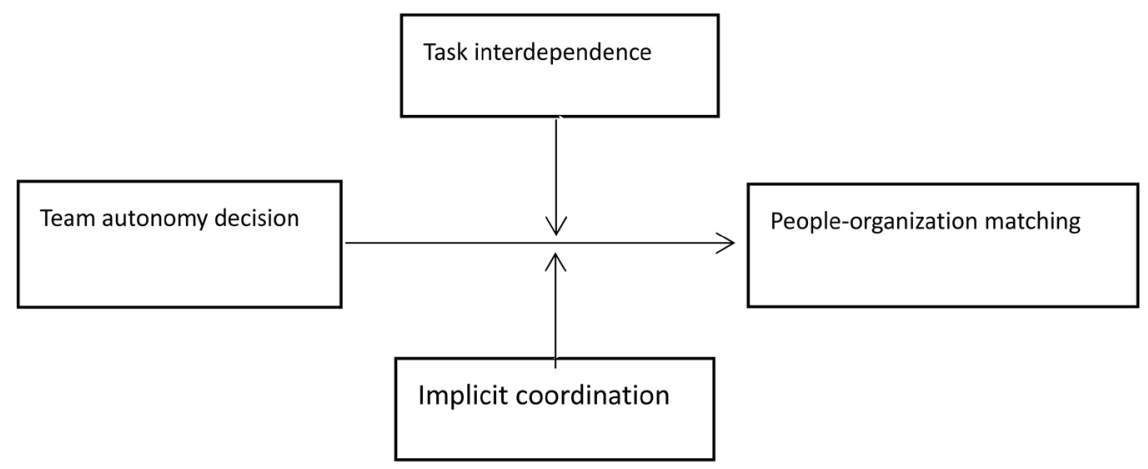

Figure 2. Research model.

and human-organization.

Based on the above assumptions, the research model of this paper can be expressed as the following form (Figure 2).

\section{Research Method}

\subsection{Sample and Data Collection}

According to the hypothesis and theoretical statement of this paper, this paper selects 41 high-tech enterprises with innovative and large-scale enterprises, and interviews the work teams of the selected enterprises through interviews. A total of 80 work teams are selected to fill out the questionnaire. Through the online questionnaire survey, the questionnaire was collected from 2018.9. A total of 415 questionnaires were collected. Through the analysis and screening process, 115 invalid questionnaires were deleted. The effective questionnaire was 300 , and the effective rate was $72 \%$.

\subsection{Variable Measurement}

In order to ensure the reliability and validity of the questionnaire, this paper draws on the mature scales at home and abroad and makes reasonable adjustments through the actual problems in the team survey, using a seven-level scale ( 1 means completely disagree, 7 means complete agreement). The team's creativity is measured by the mature scales used by Luo, Y., Li, G., \& Liu, H. The scale includes three items: "team output is creative". The internal consistency coefficient is 0.73 , which can be used. The implicit coordination of the team is measured by a scale developed by Khan et al., which means that the total of implicit coordination includes eight items such as "the behavior of team members can predict other members without communication". The internal consistency coefficient is 0.87 . The group's decision-making is based on the scales used by Gonzalez-Mule, E., Courtright, SH, Degeest, D., Seong, JY, \& Hong, DS, etc. The study also showed that it can be applied. The scale includes five items such as "our boss let my team make decisions". The internal consistency coefficient of the scale is 0.62 , which has good reliability.

Task interdependence is a scale developed by Campion et al. (1993). The scale 
includes three items, "I can't get the job done without work information or materials from other members.". The internal consistency coefficient is 0.894 . The matching between human and organization is a scale developed by Cable et al. The scale includes four items, such as matching human and organizational values, and requires ability matching. The internal consistency coefficient of the scale is 0.81 , which has good reliability. In addition, the age group, company size, education, and number of team members are selected as control variables.

\section{Empirical Analysis}

\subsection{Reliability and Validity Analysis}

The data collected by the questionnaire was analyzed by SPSS.20 for the reliability and validity of the questionnaire. The results are shown in Table 1 . The results show that the alpha values of team autonomy decision scale, human-organization matching scale, task interdependence and team implicit coordination are all greater than 0.7 , indicating that the internal consistency of the research scale is high and the reliability is good. The results show that the KMO values of the Team Creation Power Table, Human and Organization Matching Scale, Task Interdependence Scale, and Team Implicit Coordination Scale are both greater than 0.5 , and Bartlett's Sig value is 0.000 , indicating the amount of research. The validity of the table is good. The reliability and validity of the scale in this paper are in line with the research requirements, which provides data support for the next research.

\subsection{Confirmatory Factor Analysis of Variables}

Using Amos to perform confirmatory factor analysis on the main variables in this study, the data processing results show that the four-factor model has the best fit, with / df being $1.079<3$, RMSEA being $0.016<0.08$, and NIF being 0.788 . The CFI and TLI are 0.975 and 0.981 , respectively. The data of these two indicators are close to 1, indicating that the prediction model is ideal. Except that the RMSE is 0.016 , it obviously meets the requirements of pattern fitting, indicating that there is a comparison between these four variables. A good distinction further indicates that the following study can be continued in Table 2.

Table 1. Reliability and validity analysis of each variable scale.

\begin{tabular}{cccc}
\hline variables & $\alpha$ & KMO & Sig \\
\hline Team decision & 0.886 & 0.839 & 0.000 \\
Task interdependence & 0.849 & 0.729 & 0.000 \\
Implicit coordination & 0.939 & 0.954 & 0.000 \\
People-organization matching & 0.858 & 0.732 & 0.000 \\
\hline
\end{tabular}

Table 2. Verify line factor analysis.

\begin{tabular}{cccccc}
\hline Variables & $x^{2} / \mathrm{df}$ & RMSEA & NIF & CFI & TLI \\
\hline Model & 1.079 & 0.016 & 0.788 & 0.975 & 0.981 \\
\hline
\end{tabular}




\subsection{Correlation Analysis of Individual Variables}

Correlation analysis was performed on each variable by SPSS20.0, and the results were as shown. The results show that team creativity, team implicit coordination and task interdependence are significantly positively correlated with the matching of people and organizations. Therefore, through the correlation analysis of variables, it is preliminarily verified that hypothesis 1 is established. Control variables and human-to-organization match are less significant correlations, and there may be reasons for insufficient sample size, but studies have shown that control variables have a significant effect on models with little influence. At the same time, in order to prevent the occurrence of multi-collinearity problem, the VIF test is further carried out. The highest variance expansion of each variable is $7.730<10$, which indicates that the model and the research hypothesis are reasonable, and the variables can be further verified in Table 3.

\subsection{Main Effect Test}

In order to test the relationship between team autonomy and human-organization matching, linear regression is performed by Spss. According to the steps of linear regression, the control variables, namely employee age, gender, education, team size and independent variable team decision-making, are introduced into the model 1 to verify the relationship between the team's self-determination and the person-organization matching. It shows that the independent variable has a significant positive correlation with the dependent variable, which proves the establishment of $\mathrm{H} 1$. The specific results can be seen in Table 4. It also shows that when the high-tech enterprise team has higher autonomy in personnel decision-making, it will help people-organization match.

\subsection{Adjustment Effect Test}

For the test of the regulatory variables, this paper adopts the hierarchical regression method. On the basis of model 1 , the adjustment variables-task interdependence and implicit coordination are introduced into model 2. Secondly, centralize the

Table 3. Person correlation coefficient of study variables.

\begin{tabular}{cccccccccc}
\hline & Mean & $\begin{array}{c}\text { Standard } \\
\text { deviation }\end{array}$ & 1 & 2 & 3 & 4 & 5 & 6 & 7 \\
\hline generation & 2.94 & 1.184 & 1 & & & & & \\
Education & 2.01 & 0.76 & -0.51 & 1 & & & & \\
Team size & 2.6 & 1.051 & $-0.073^{*}$ & 0.056 & 1 & & & & \\
Self-determination & 5.85 & 1.004 & 0.01 & 0.036 & 0.059 & 1 & & & \\
Implicit coordination & 5.80 & 1.13 & -0.003 & -0.023 & 0.002 & $0.731^{* *}$ & 1 & & \\
Task interdependence & 5.74 & 1.22 & 0.012 & 0.006 & -0.032 & $0.692^{* *} 0.859^{* *}$ & 1 & \\
People-organization & 5.87 & 0.75 & -0.03 & -0.041 & 0.033 & $0.701^{* *} 0.707^{* *} 0.657^{* *}$ & 1 \\
matching & & & & & & & & & \\
\hline
\end{tabular}

Note: ${ }^{*}$ Significantly correlated at 0.05 level (both sides), ${ }^{*}$ Significantly correlated at .01 level (both sides). 
Table 4. Test of adjustment effect.

\begin{tabular}{cccc}
\hline \multirow{2}{*}{ Variable } & \multicolumn{3}{c}{ People-organization matching } \\
\cline { 2 - 4 } & model 1 & model 2 & model 3 \\
Generation & -0.023 & -0.023 & -0.022 \\
Education & -0.051 & -0.065 & $-0.72^{\star}$ \\
Team size & $0.11^{*}$ & $0.021^{*}$ & 0.02 \\
Self-determination & $0.282^{* *}$ & $0.35^{* *}$ & $0.376^{* *}$ \\
Implicit coordination & $0.187^{*}$ & $0.200^{* *}$ & $0.286^{* *}$ \\
Task interdependence & 0.108 & $0.187^{* *}$ & $0.107^{*}$ \\
Autonomous decision-making $\times$ task interdependence & & $0.012^{* *}$ & \\
Self-determination $\times$ implicit coordination & \multicolumn{3}{c}{$0.119^{* *}$} \\
$R^{2}$ & 0.583 & 0.610 & 0.621 \\
F value & $68.324^{* *}$ & $65.204^{* *}$ & $68.445^{* *}$ \\
$\Delta R^{2}$ & \multicolumn{2}{c}{0.027} & 0.038 \\
\hline
\end{tabular}

team's independent decision-making, task-dependent variables and implicit coordination, and multiply the implicit and task-dependent variables after centralization and the team's independent decision to form two interactive terms. The team independent decision-making and task-interdependence interaction items are added to the model 2 . In Table 4 , it can be seen that the task interdependence has a significant positive adjustment effect between the team self-determination decision and the person-organization match $(\beta=0.012, \mathrm{P}<0.05)$. That is to say, the research hypothesis that $\mathrm{H} 2$ is proved to be established, that is, the higher the interdependence of tasks, the stronger the relationship between team autonomy and human-organization matching. Task interdependence indicates that in the team work situation, the connection between the work content of the employee's home is tight, requiring the staff to achieve the connection of the work content, and the selection of the new person is not only capable of having the ability to match the organization. The trait, and the ability to understand the ability of the work in the team to understand the ability to work and the ability to complete the cooperation is the team staff, this level determines the team's decision-making is far more than other Decision makers are more effective.

On the basis of model 1, the interaction items of task interdependence, implicit coordination, team autonomy decision and implicit coordination are introduced into model 3, thereby verifying the adjustment effect of implicit coordination. As can be seen in Table 4, the interaction term has a significant positive adjustment effect on team autonomy decision-making and human-organization matching $(\beta=0.119, \mathrm{P}<0.05)$. Implicitly coordinated research origins and teamwork, implicitly coordinating the role of mediator variables in more literature, not in terms of research team output or team creativity, implicit coordination as a mediator variable is more suitable Can better explain the mechanism of influence between variables. In this paper, the implicit coordination as a mod- 
erator to study the relationship between team autonomy and human-organization matching is based on the principle of goal fusion. In a very distinctive way of working-teamwork, implicit coordination can not only promote the efficient completion of work tasks, but also make employees more effective. From the perspective of social psychology, it can be seen that the human being needs to be stimulated and stimulates a person's deeper desire for expression. This proves the establishment of $\mathrm{H} 3$.

In order to further understand the effect of the adjustment variable on the relationship between the independent variable and the dependent variable, by making two adjustment variables on the main effect of the adjustment effect diagram.

\section{Research Conclusions and Management Recommendations}

This paper starts from the typical team work level of high-tech enterprises, chooses the subject of recruitment for this kind of post with special requirements, and proposes the recruitment model based on the research confirmed by this paper-team independent decision-making. The research results show that in the existing high-tech industry, the high-tech enterprises in the way of team work, the team's self-determined recruitment decision will make the person-organization matching more efficient, reduce the employee's turnover tendency and motivate the employees' work enthusiasm. The mechanism of action is discussed from the characteristics of team work. Task interdependence and implicit coordination require the professionalism of the staff in the work. Task interdependence excepts the professional requirements of the work which should reflect the heterogeneity requirements of the team staff; that do not need too much field consistency Professionals, but also need professional talents in other related fields. Recruitment strategies based on the above work requirements not only avoid blind "talent pools", but also purify and make the best use of the "talent pool" within the enterprise. The cost of the recruitment method has higher capital cost and labor cost than the traditional recruitment. However, using the "learning by doing" principle in economics, the company will get more return profits in the future talent value.

This paper lays the foundation for the internal logic of the relationship between variables in the context of social exchange theory, goal fusion theory, and Maslow's hierarchy of needs. The empirical results prove the authenticity of the hypothesis, but it should be noted that the proposed recruitment method in this paper does not apply to all enterprises. The research in this article is inspired by the understanding of Bell Labs. It is hoped that domestic companies will have similar mechanisms with Bell Labs that seem to be perpetually creating new products and absorbing new talents. Of course, due to the differences in humanities between the two countries, it is also suitable for the humanistic characteristics of countries in terms of researching employees. In China, there are no fewer studies on the characteristics of employees. Learning the talent management mechanism and talents of Bell will bring us meaning. At present, Haier Group 
has already delegated the decision-making power of personnel to each individual work team, and research shows that this new management method brings Haier unlimited vitality and motivates employees to develop their potential.

Enterprises with mature domestic scale and high-tech industries should adapt to the changes of the times and the needs of talents. They should not only motivate employees economically, but also identify and motivate the inner potential of employees after identifying their existing capabilities. The research by Peter Kapelley, a professor of management at Wharton School of the United States, found that "what do you value most about a job?" is the first thing that "gets something helpful for the next job". This is enough to prove that the needs of employees are not only economic satisfaction, but also more opportunities for "self-learning". According to the 2017 data, the common traits of the top three companies, Alibaba, Huawei, and Bank of China, are to provide "learning opportunities", and this is a magic weapon for them to attract more talents.

This paper studies the decision-making problem of recruitment from the perspective of team work and people-organization matching, which is more in line with the working mode of the current enterprise, but the research is still not complete enough. First, in the sample acquisition, we have not studied various types of enterprise characteristics, but only select high-tech enterprises, although from the theoretical point of view, traditional enterprises are not suitable for team-based decision-making recruitment methods, when the suitability of enterprises in other industries is still for further discussion. Second, this paper mainly considers the effectiveness and influencing factors of recruitment from the perspective of enterprises. It is not possible to consider recruitment methods or decision-making from the perspective of employee characteristics. It is a level worthy of attention for future research. Third, the market is dynamic, and the enterprise is also advancing in the process of change. The future of recruitment research should focus on dynamic decision-making and changes in methods. In research, more research should be added to the factors that lead to corporate change, as well as candidates. Research should be paired with research, and such research can make its conclusions more theoretical and practical.

Therefore, this paper makes the following recommendations for future research on this aspect. The recruitment model, the status of human resources, or the value orientation of employees can be studied from other levels. Get more microscopic data to further explore the use of recruitment models in different organizational structures and the use of tiered research for different levels of recruitment.

\section{Conflicts of Interest}

The authors declare no conflicts of interest regarding the publication of this paper. 


\section{References}

[1] Jiang, L., Yu, G.T. and Li, Y.J. (2007) Team Decision and Its Influencing Factors. Advances in Psychological Science, 15, 358-365

[2] Ming, Y. (2014) Make the Recruitment to the Extreme.

[3] Davis, J.H., Kameda, T., Parks, C., et al. (1989) Some Social Mechanics of Group Decision Making: The Distribution of Opinion, Polling Sequence, and Implications for Consensus. Journal of Personality and Social Psychology, 57, 1000-1012. https://doi.org/10.1037/0022-3514.57.6.1000

[4] Ganster, D.C., Williams, S. and Poppler, P. (1991) Does Training in Problem Solving Improve the Quality of Group Decisions? Journal of Applied Psychology, 76, 479-483. https://doi.org/10.1037/0021-9010.76.3.479

[5] Stasser, G., Taylor, L.A. and Hanna, C. (1989) Information Sampling in Structured and Unstructured Discussions of Three- and Six-Person Groups. Journal of Personality and Social Psychology, 57, 67-78. https://doi.org/10.1037/0022-3514.57.1.67

[6] Ilgen, D.R. (1999) Teams Embedded in Organizations: Some Implications. American Psychologist, 54, 129-139. https://doi.org/10.1037/0003-066X.54.2.129

[7] Wan, H. (2012) A Preliminary Study on China's Green Human Resource Management from the Perspective of AMO Theory-A Micro-Research Perspective. China Human Resources Development, No. 10, 9-13.

[8] Wu, W.Y. (2005) On the Establishment of Recruitment Team in Modern Enterprises. China Human Resources Development, No. 9, 35-37.

[9] Ang, Q.R., Li, Y.J., Wang, J.F. and Feng, J.Z. (2008) College Laboratory Construction and Innovative Talent Training. Science and Technology Management Research, 28, 227-234.

[10] Zhang, K. (2003) New Explanation of Incentive Theory. Scientific Management Research, No. 2, 89-92+98.

[11] Kristof, A.L. (1996) Person-Organization Fit: An Integrative Review of Its Conceptualizations, Measurement, and Implications. Personnel Psychology, 49, 1-49. https://doi.org/10.1111/j.1744-6570.1996.tb01790.x

[12] Vancouver, J.B. and Neal, W.S. (1991) An Exploratory Examination of Person-Organization Fit: Organizational Goal Congruence. Personnel Psychology, 44, 333-352. https://doi.org/10.1111/j.1744-6570.1991.tb00962.x

[13] Wageman, R. (1995) Interdependence and Group Effectiveness. Administrative Science Quarterly, 40, 145-180. https://doi.org/10.2307/2393703

[14] Wang, Y.Z., Luo, W. and Shi, J.T. (2014) Research on the Influence Mechanism of Task Interdependence on Team Creativity. Science and Technology Progress and Countermeasures.

[15] Wang, Y.Z., Luo, W. and Shi, J.T. (2014) Tasks Research on the Influence Mechanism of Team Effectiveness on Team Creativity. Science and Technology Progress and Countermeasures.

[16] Stewart, G.L. and Barrick, M.R. (2000) Team Structure and Performance: Assessing the Mediating Role of Intrateam Process and the Moderating Role of Task Type. Academy of Management Journal, 43, 135-148. https://doi.org/10.5465/1556372

[17] Ramamoorthy, N. and Flood, P.C. (2004) Individualism/Collectivism, Perceived Task Interdependence and Teamwork Attitudes among Irish Blue-Collar Employees: A Test of the Main and Moderating Effects? Human Relations, 57, 347-366. https://doi.org/10.1177/0018726704043274 
[18] Kiggundu, M.N. (1981) Task Interdependence and the Theory of Job Design. Academy of Management Review, 6, 499-508. https://doi.org/10.5465/amr.1981.4285795

[19] Campion, M.A., Papper, E.M. and Medsker, G.J. (1993) Relations between Work Team Characteristics and Effectiveness: A Replication and Extension. Personnel Psychology, 46, 823-850. https://doi.org/10.1111/j.1744-6570.1993.tb01571.x

[20] Wittenbaum, G.M., Stasser, G. and Merry, C.L. (1996) Tacit Coordination in Anticipation of Small Group Task Completion. Journal of Experimental Social Psychology, 32, 129-152. https://doi.org/10.1006/jesp.1996.0006 